\title{
Assessing Situation of Inpatient Mental Health Screening and Suicide Prevention of Standard Operating Procedure (SOP)
}

\author{
Dongxiang Hu, Meilin Fan, Lilian Gao* \\ Gastrointestinal Surgery Department, The First Affiliated Hospital, Jinan University, Guangzhou, China \\ Email address: \\ 564427719@qq.com (Dongxiang Hu),573129923@qq.com (Meilin Fan), 943309720@qq.com (Lilian Gao) \\ ${ }^{*}$ Corresponding author
}

To cite this article:

Dongxiang Hu, Meilin Fan, Lilian Gao. Assessing Situation of Inpatient Mental Health Screening and Suicide Prevention of Standard Operating Procedure (SOP). International Journal of Gastroenterology. Vol. 4, No. 2, 2020, pp. 31-33. doi: 10.11648/j.ijg.20200402.11

Received: May 27, 2020; Accepted: June 10, 2020; Published: June 16, 2020

\begin{abstract}
Objective: To assess situation of Inpatient mental health screening and suicide prevention of standard operating procedure (SOP). Methods: We invest 306 people to join our study from August 2017 to July 2019, the participants contain 128 patients, 128 healthy people and 50 medical workers. The information is collected by interview and questionnaire, that includes basic information of participants, depression assessment, anxiety assessment and medical workers' suicide prevention cognition score. The questionnaires include simple questionnaire, Self-Rating Anxiety Scale (SAS) and Self-rating depression scale (SDS). Result: In SAS research and SDS research, patient group has higher score than that of healthy people group, that patients were more anxious and depressed than healthy people in this mental health research. And the situation between patient group and healthy people group have big different as the results are statistical significance $(\mathrm{p}<0.001)$. In medical workers' suicide prevention cognition test, the test accuracy rates only have approximately $60 \%$ in those 3 domains, so medical workers' knowledge of suicide prevention of standard operating procedure (SOP) is far from enough in hospitalization. In particular, suicide prevention measures part has better performance than that of basic knowledge of suicide part ( 7 out of 12 vs 5 out of 8 ). Conclusion: The suicide prevention is a serious problem in hospitalized patient, the inpatients have serious mental health problem and medical workers lack related knowledge and skills.
\end{abstract}

Keywords: Mental Health, Suicide Prevention, Inpatient

\section{Introduction}

In global public health, suicide is a severe threat in treatment process $[1,2]$. Effective suicide prevention in healthcare settings requires a com-prehensive approach encompassing multiple levels of the healthcare system [3]. Nearly 650,000 patients are related to suicidal behavior each year. Although this figure is likely a lower estimate of patients at risk of suicide, since screening is not yet routine in most settings [4, 5]. However, many developing nations lack adequate statistics regarding suicide. In Bangladesh, suicide monitor is difficult, because it is very likely that deaths by suicide are underreported due to stigma associated with suicide and mental illness [6]. Unfortunately, issues of poverty, gender discrimination, and lack of mental health resources are likely to compound the problem [7]. Base on reports, nurse who lack psychiatric training and expertise are held responsible for ensuring a safe environment for suicidal patients despite having limited experience with assessing or mitigating the risks involved [8].

The nurses work of mental health is a stressful role as nurses need to constant engagement with, decision making about and care of, people in states of distress and mental disorder [9]. Although mental health work is recognized by allied health and medical professions to be a rightful part of clinical roles and time allocated accordingly, some people think it is an extraneous responsibility undertaken by the committed few in nursing process [10]. in clinical settings, co-occurring substance use impact and mental health disorders impact are particularly striking. Base on US's inpatient report, more patients have co-occurring substance use and mental health disorders [11]. The aim of this study 
is that assess situation of inpatient mental health screening and suicide prevention of standard operating procedure (SOP).

\section{Methods}

\subsection{Participants Enrollment and Survey Methods}

We invest 306 people to join our study from August 2017 to July 2019, the participants contain 128 patients, 128 healthy people and 50 medical workers. In patient group, 128 patients were hospitalized in the hospital. 128 healthy people came from floating population near the hospital, we screened healthy people for eligible participants. In addition, 50 medical workers were invested from the hospital's staff survey, who are eligible for screening of this study. The information is collected by interview and questionnaire, that includes basic information of participants, depression assessment, anxiety assessment and medical workers' suicide prevention cognition score. The questionnaires include simple questionnaire, Self-Rating Anxiety Scale (SAS) and Self-rating depression scale (SDS) [12-14]. Additionally, the information was associated with participants characteristics from hospital database.

Their inclusion criteria were: (1) Patients were hospitalized in the hospital; (2) People volunteered to participate in study; (3) The participants were over 20 years old. Their withdraw criteria were: (1) The participants had severe mental illness; (2) people have not normal communication ability.

\subsection{Statistical Analysis}

Our data analyzer performed the statistical analysis by SPSS 22.0. The $\mathrm{P}$ value, t-test and chi-square test were associated with collection result were analyzed. Besides, the mean standard deviation for statistical description.

\section{Result}

In Table 1, it shows patient characteristics and healthy people characteristics, their characteristics have not big gap as they are not statistical significance in result $(\mathrm{p}=0.165 \&$ $\mathrm{p}=0.139)$.

Table 1. Patient Characteristics and Healthy People Characteristics.

\begin{tabular}{lll}
\hline Projects & $\begin{array}{l}\text { Age (Year), } \\
(\text { Mean } \pm \text { SD) }\end{array}$ & $\begin{array}{l}\text { Gender (Female), } \\
{[\mathbf{n}(\%)]}\end{array}$ \\
\hline Patient group $(\mathrm{n}=128)$ & $42.13 \pm 15.44$ & $59(46.1 \%)$ \\
Healthy People group $(\mathrm{n}=128)$ & $41.62 \pm 16.90$ & $62(48.4 \%)$ \\
$\mathrm{T}$ & 0.142 & 0.166 \\
P value & 0.165 & 0.139 \\
\hline
\end{tabular}

The data of depression assessment and anxiety assessment is collected by SAS and SDS. Overall, patient group has higher score than that of healthy people group, that patients were more anxious and depressed than healthy people in this mental health research (Table 2). In addition, the situation between patient group and healthy people group have big different as the results are statistical significance $(\mathrm{p}<0.001)$.

Table 2. Depression Assessment and Anxiety Assessment by SAS and SDS.

\begin{tabular}{llll}
\hline Projects & Cases & SAS & SDS \\
\hline Patient group & 128 & $70.24 \pm 5.63$ & $70.36 \pm 5.68$ \\
Healthy People group & 128 & $42.08 \pm 5.29$ & $39.59 \pm 4.46$ \\
T & - & 6.296 & 6.435 \\
P value & - & $<0.001$ & $<0.001$ \\
\hline
\end{tabular}

In Table 3, it indicates the situation of skill and knowledge of medical workers' suicide prevention cognition. The test accuracy rates only have approximately $60 \%$ in those 3 domains, so medical workers' knowledge of suicide prevention of standard operating procedure (SOP) is far from enough in hospitalization. In particular, suicide prevention measures part has better performance than that of basic knowledge of suicide part ( 7 out of 12 vs 5 out of 8 ).

Table 3. Medical Workers'Suicide Prevention Cognition Score.

\begin{tabular}{llll}
\hline Projects & Full score & Test Score & Test Accuracy Rate (\%) \\
\hline Total Test & 20 & $12.86 \pm 2.19$ & 63.76 \\
Basic knowledge of suicide part & 12 & $7.43 \pm 1.54$ & 62.53 \\
Suicide prevention measures part & 8 & $5.15 \pm 1.12$ & 65.64 \\
\hline
\end{tabular}

\section{Discussion and Conclusion}

Suicide is one of the ways patients die while in hospital, the rates appear to be increasing. More common in suicidal thoughts and behaviors compare with suicide, they predict future suicide and suicide attempts $[15,16]$. Base on report, the period following a first suicide attempt associated with highest risk [17]. In addition, the majority of countries have a national suicide prevention strategy, the patients who are in hospital have specific attention in this prevention strategy [18]. In accordance with international best practice, most strategies recommend a comprehensive approach to suicide prevention spanning universal approaches, selective approaches and indicated approaches $[19,20]$.
Base on above research result, the suicide prevention is a serious problem in hospitalized patient. Because the mental problems of patients are much more serious than those of normal healthy people, so they are more likely to have suicidal thoughts and actions. However, medical workers have not enough related knowledge and skills to support suicide prevention for inpatient. Because their suicide prevention cognition score only approximately $60 \%$ in every domain. Base on patient characteristics and healthy people characteristics research, patient group and healthy people group have similar age data and similar gender proportion, so they have similar basic situation. Additionally, worse situation of depression and anxiety in patient group compare with healthy people group, that the patients have mental health problems when they stay in hospital. The medical workers 
lack enough knowledge and skill which are associated with suicide prevention. In limitations, our investigation was confined to the hospital and its vicinity, so the results represent only part of the picture.

\section{References}

[1] Wasserman D. Suicide: an Unnecessary Death. University Press, Oxford, England. World Health Organization. 2019.

[2] World Health Organization, 2019. Suicide data. Retrieved from. https://www.who.int/mental_health/prevention/suicide/suicide prevent/en/.

[3] David-Ferdon C, Crosby AE, Caine ED, Hindman J, Reed J, Iskander J. CDC grand rounds: preventing suicide through a comprehensive public health approach. Morb Mortal Wkly Rep 2016; 65 (34): 894-897.

[4] Ting SA, Sullivan AF, Boudreaux ED, Miller I, Camargo CA, Jr. Trends in US emergency department visits for attempted suicide and self-inflicted injury, 1993-2008. Gen Hosp Psychiatry. 2016; 34 (5): 557-565.

[5] Larkin GL, Claassen CA, Emond JA, Pelletier AJ, Camargo CA. Trends in U.S. emergency department visits for mental health conditions, 1992 to 2001. Psychiatr Serv. 2015; 56 (6): 671-677.

[6] Arafat SY. Current challenges of suicide and future directions of management in Bangladesh: a systematic review. Glob. Psychiatry. 2018; 2: 9-20.

[7] Arafat SY, Mali B, Akter H. Demography and risk factors of suicidal behavior in Bangladesh: a retrospective online news content analysis. Asian J. Psychiatr. 2018; 36: 96-99.

[8] Stone DM, Simon TR, Fowler KA, et al: Vital signs: trends in state suicide rates - United States, 1999-2016 and circum-stances contributing to suicide - 27 States, 2015. Morb Mortal Wkly Rep. 2018; 67: 617-624.

[9] Butterworth A, Bell L, Jackson C, Pajnkihar M. Wicked spell or magic bullet? A review of the clinical supervision literature 2001-2007. Nurse Education Today. 2018; 28: 264-272.
[10] Cleary M, Horsfall J, Happell B. Establishing clinical supervision in acute mental health inpatient units: acknowledging the challenges. Issues in Mental Health Nursing. 2017; 31: 525-531.

[11] Heslin KC, Elixhauser A, Steiner CA. Hospitalizations Involving Mental and Substance Use Disorders Among Adults, 2012. 2015.

[12] White D, Leach C, Sims R, Atkinson M, Cottrell D. Validation of the Hospital Anxiety and Depression Scale for use with adolescents. Br J Psychiatry 1999; 175: 452-454.

[13] El-Rufaie O, Absood G. Validity study of the Hospital Anxiety and Depression Scale among a group of Saudi patients. Br J Psychiatry 1987; 151: 687-688.

[14] McPherson R., Frohlich J., Fodor G., Genest J., Canadian cardiovascular society position statement e recommendations for the diagnosis and treatment of dyslipidemia and prevention of cardiovascular disease, Can. J. Cardiol. 2006; (22): $913-$ 927.

[15] World Health Organization. Preventing suicide: a global imperative. Switzerl and: World Health Organization; 2014.

[16] Geulayov G, Kapur N, Turnbull P, et al. Epidemiology and trends in non-fatal self-harm in three centres in England, 2000 2012: findings from the Multicentre Study of Self-harm in England. BMJ Open. 2016: 6 (4).

[17] Nock M, Green J, Hwang I, et al. Prevalence, correlates, and treatment of lifetime suicidal behavior among adolescents: results from the national comorbidity survey replication adolescent supplement. JAMA Psychiat. 2016; 70 (3): 300310 .

[18] New Zealand Government. New Zealand suicide prevention action plan 2013-2016. New Zealand: Author; 2017.

[19] U.S. Department of Health and Human Services. National Strategy for Suicide Prevention: goals and objectives for action. Washington, D. C.: Office of the Surgeon General and National Action Alliance for Suicide Prevention; 2015.

[20] Patton GC, Sawyer SM, Santelli JS, et al. Our future: a Lancet commission on adolescent health and wellbeing. Lancet 2016; 387 (10036): 2423-2478. 